\title{
SURFACE MODELING FOR CAD/CAM BASED ON NURBS
}

\author{
Tat-Hien Le ${ }^{(1)}$, Nguyen Xuan Hung ${ }^{(2)}$, Vo Trong Cang ${ }^{(1)}$
}

(1) University of Technology, VNU-HCM

(2) University of Science, VNU-HCM

(3) University of Technology, VNU-HCM

(Manuscript Received on May $16^{\text {th }}$ 2011, Manuscript Revised January 01 ${ }^{\text {st }}$ 2012)

ABSTRACT: In the digital design process, surface modeling is required to be as accurate as possible for the effective support of production as well as for numerical performance analysis. This article reviews the geometric modeling techniques, based on non-uniform rational B-spline (NURBS). The NURBS surface can be readily translated into many CAD/CAM packages (Computer Aided Design/Computer Aided Manufacturing), which is more convenient for visualization performance and finite element methods.

Key words: Surface modeling, NURBS, CAD/CAM, visualization.

\section{INTRODUCTION}

Surface modeling is the key to integration of design, analysis, manufacturing, and other calculation [3]. There are two principle categories for surface fitting techniques. The first one works with reverse engineering in two steps; first the given data points are rearranged into the rectangular mesh, then the surface is constructed by some matrices inversion and Bspline algorithm procedures. The first problem is that the data points are often scattered. The second problem comes from the matrices inversion. In fact, the matrices inversion gets the ill conditioned problem, and it must also avoid round off error magnifications in backsubstitution calculation and large storage capacity. The second surface generation technique is to approximate the given data points by B-spline algorithm. Many conventional methods have been proposed
$[8,1]$. The main problem is the parameterization of B-spline surface. It needs to be estimated from an initial unknown surface. The approximation of surface fitting using genetic algorithm is developed by Birmingham [5], Le et al [6]. However, this method gets stuck in case of complicated surfaces. The main contribution of this research is to use non uniform B-spline (NUB) surface fitting through a GA technique. This approach has more advantages with regard to surface representation, and fairness of the interior surface.

2. OVERVIEW OF THE B-SPLINE FITTING ALGORITHM

Surface fitting basis

B-spline surface data $\mathrm{D}(\mathrm{u}, \mathrm{w})$ is given by:

$$
D(u, w)=\sum_{i=1}^{n+1} \sum_{j=1}^{m+1} B_{i, j}^{h} N_{i, k}(u) M_{j, l}(w)
$$


Let $\mathrm{x}_{\mathrm{i}}$ and $\mathrm{y}_{\mathrm{j}}$ be knots value and $\mathrm{B}_{\mathrm{i}, \mathrm{j}}$ is the vertex point of $\mathrm{B}$-spline for data fitting, and $\mathrm{Ni}, \mathrm{k}(\mathrm{u})$ and $\mathrm{Mj}, \mathrm{l}(\mathrm{w})$ are the basis functions. Eq. 1 shows that shape of NUB surface will be regenerated if we change the location of vertex point and knot value, as in Fig. 1. In GA process, we changed the shape of surface automatically in this way. Therefore, the final surface can get the good solution time by time.

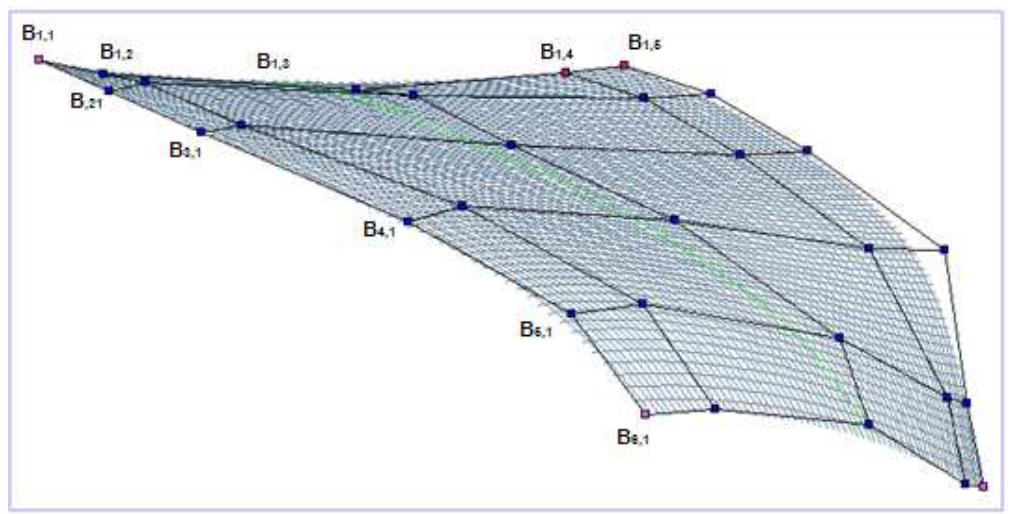

Fig 1. Rectangular vertex points

\subsection{Matrices Inversion Problems in B-spline}

Fitting

Generally speaking, many conventional methods have been proposed in NUB surface fitting. Writing Eq. (1) for each single B-spline data point yields

$$
\begin{aligned}
& D_{1,1}\left(u_{1}, w_{1}\right)= \\
& \quad N_{1, k}\left(u_{1}\right)\left[M_{1, l}\left(w_{1}\right) B_{1,1}+M_{2, l}\left(w_{1}\right) B_{1,2}+\ldots+M_{m+1}\left(w_{1}\right) B_{1, m+1}\right]+ \\
& \quad \cdot \\
& \quad \cdot \\
& \quad \cdot \\
& \quad N_{n+1, k}\left(u_{1}\right)\left[M_{1, l}\left(w_{1}\right) B_{n+1,1}+M_{2, l}\left(w_{1}\right) B_{n+1,2}+\ldots+M_{m+1}\left(w_{1}\right) B_{n+1, m+1}\right]
\end{aligned}
$$

In the matrix form of NUB surface point of Eq. (2), moving in space with 2 degrees of freedom, $\mathrm{u}$ and $\mathrm{w}$, is given by:

$$
[D]=[C][B]
$$

Where [D] is an $\mathrm{r} \times \mathrm{s} x 3$ matrix containing the $3 \mathrm{D}$ coordinates of surface data points, $[\mathrm{C}]$ is an $\mathrm{r} \times \mathrm{s} \times \mathrm{n} \times \mathrm{m}$ matrix of the products of the basis functions, and [B] is an $\mathrm{n} \times \mathrm{m} \times 3$ matrix of the $3 \mathrm{D}$ coordinates of the required vertices.

If $[\mathrm{C}]$ is not square, the solution is given by:

$$
[B]=\left[[C]^{T}[C]\right]^{-1}[C]^{T}[D]
$$

Nevertheless, the matrix inversion gets the ill conditioned problem when determinant close to zero. The Fig. 2 illustrates the difficulties of surface fitting in matrices inversion. 


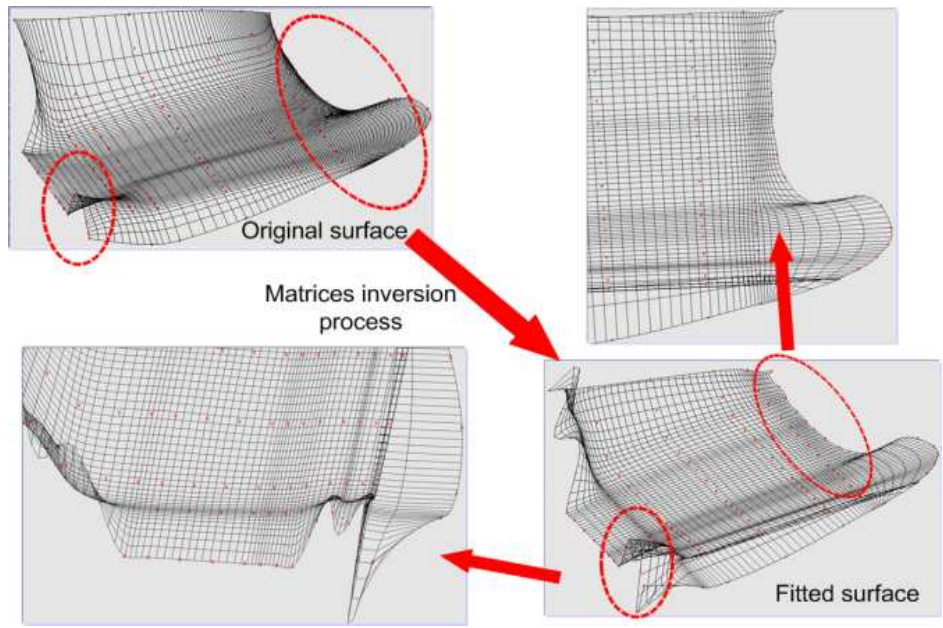

Fig 2. The difficulties of fitted surface in matrices inversion method

For curve fitting, an optimization method with GA has been presented by Yoshimoto [4]. However, the matrices inversion is not a solution for irregular given data points. Instead, moving the location of the vertex point using GA is efficient way to improve the surface quality.

\section{NEW APPROACH TO SURFACE FITTING FOR THE GIVEN INTERIOR DATA POINT BY USING GA}

\subsection{Vertices Encoding for Initial Population}

For an initial population, usually the base surface is created by vertices. The vertices can be generated with the same $\mathrm{x}$ and $\mathrm{z}$ coordinate value of the given data points and deviation $\delta$ in y direction (see in Fig. 3).
Vertex point is generated by moving given data points up or down with small deviation $\delta$

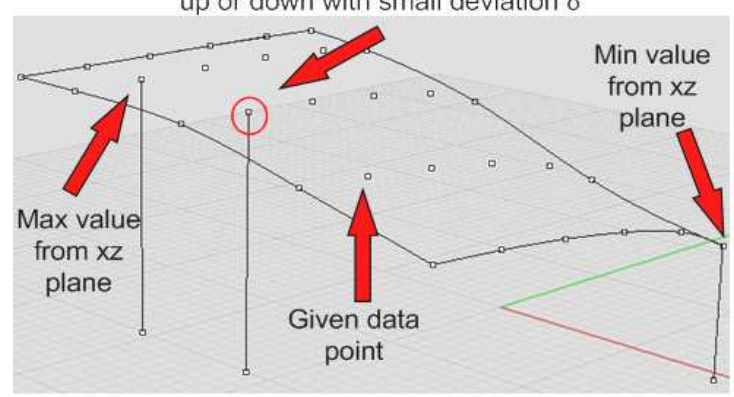

Fig 3. The generation of vertices from the given data points

\subsection{Crossover Process}

The idea here is to exchange a single knot value in two parents to form two new individuals. Fig. 4 shows that the individual 1 received a new sub-string from individual 2 to generate a new individual in a next population. 


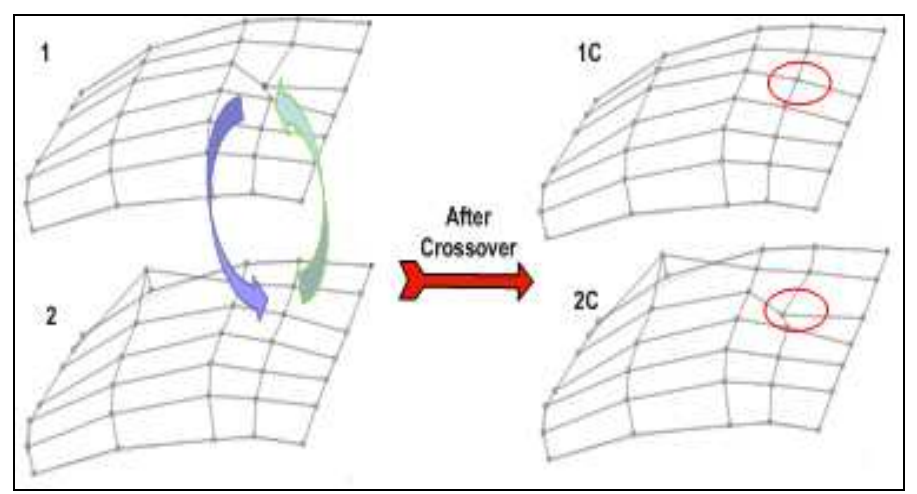

Fig 4. Crossover procedure

\subsection{Mutation Process}

In this method, the location of the new vertex point is created by moving in a circle of small radius $\delta$ around the old vertex point. In such an approach, $\delta$ should be recommended less than $5 \%$ of the distance between old vertex point and the nearest neighboring vertex point. The variable design has a deviation with the deviation size $\delta$ as given by Eq. (6).

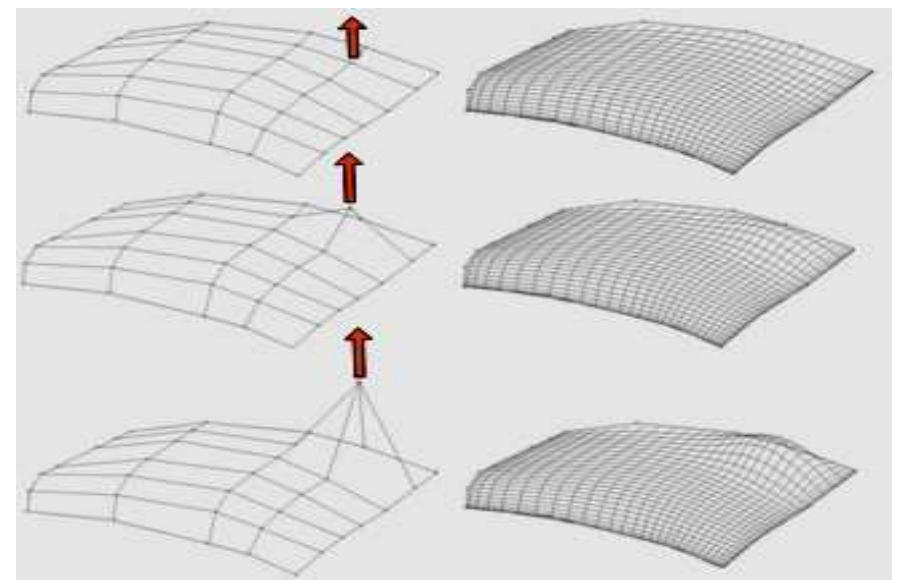

Fig 5. The effect of moving one of the vertex points of the surface

\subsection{Jacobian inversion for finding nearest points}

This can be solved by Jacobian iteration within a few steps [1]:

$$
\left[B_{\text {new }}\right]=\left[B_{\text {old }}\right]+\delta
$$

(6)

Therefore, the surface quality improves a good result after each time. Deformation of a NUB surface can be achieved by moving the vertices that define it (see Fig. 5). 


$$
\begin{aligned}
& \Delta u=\frac{\left(r_{u} \cdot d\right)\left(r_{u} \cdot r_{w}\right)-\left(r_{w} \cdot d\right)\left(r_{u} \cdot r_{w}\right)}{\left(r_{u} \cdot r_{u}\right)\left(r_{w} \cdot r_{w}\right)-\left(r_{u} \cdot r_{w}\right)^{2}} \\
& \Delta w=\frac{\left(r_{w} \cdot d\right)\left(r_{u} \cdot r_{u}\right)-\left(r_{u} \cdot d\right)\left(r_{u} \cdot r_{w}\right)}{\left(r_{u} \cdot r_{u}\right)\left(r_{w} \cdot r_{w}\right)-\left(r_{u} \cdot r_{w}\right)^{2}}
\end{aligned}
$$

4. If $(|\Delta u|>\mathcal{E})$ or $(|\Delta w|>\mathcal{E})$ then return step 2

5. else stop

6. Final step:

$$
Q=\sum_{i=1, j=1}^{N, M}\{D(i, j)-G\}^{2}
$$

In that case, the location of vertices will be optimized to fit the given data points using GA technique.

\section{APPLICATION EXAMPLES}

\section{1. Ship Hull Surface}

The Fig.6 illustrates the given data points of surface. In this case, the surface shows total error values converged at 20,000th generation and the best fitting after 20,000 generations (see Fig.7\&8). The normalized error value after 20,000 generations is computed in Table 1.

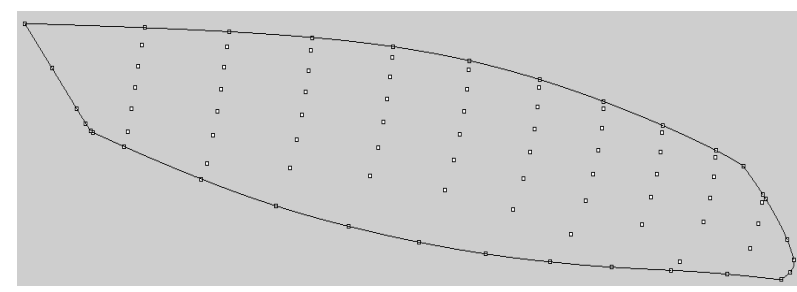

Fig 6. The given data points of yacht surface
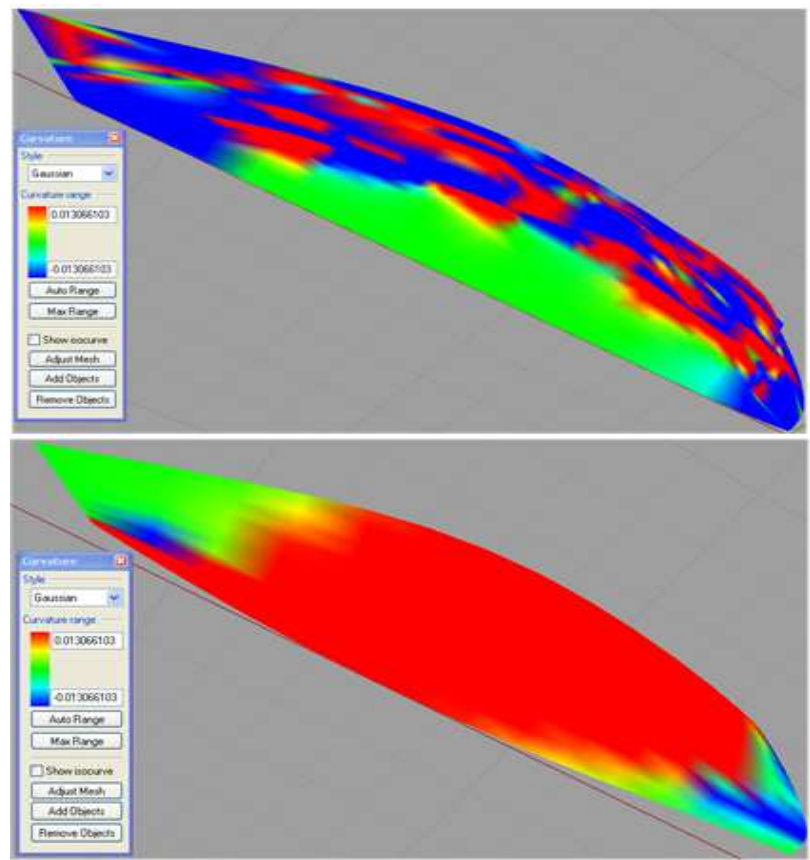

Fig 7. The Gaussian curvature of surface at 1 st generation and 20,000th generation 
Table 1. Normalized error between the given data points and the surface points

\begin{tabular}{|l|l|l|}
\hline $\begin{array}{l}\text { No. of vertex points in u Computing } \\
\text { and w directions }\end{array}$ & $\begin{array}{l}\text { Normalized } \\
\text { time }\end{array}$ & error \\
\hline $10 \times 14$ & $15 \mathrm{~min}$ & 0.0044834 \\
\hline
\end{tabular}

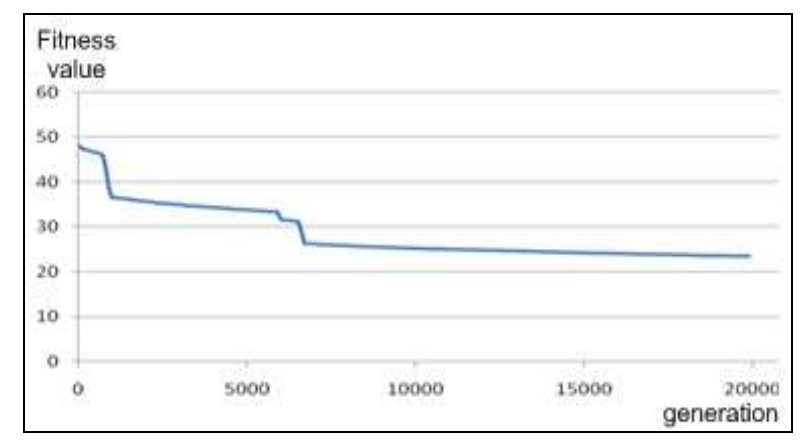

Fig 8. The fitness value during generations of complicated shape

\subsection{Complicated Surface}

The complicated mesh (Fig. 9) consists of 91 given data points. The initial result and the best result at 20,000th generation were illustrated from Fig. 10 and 11. Finally, a value of normalized error converged at the 20,000th generation (see Table 2).

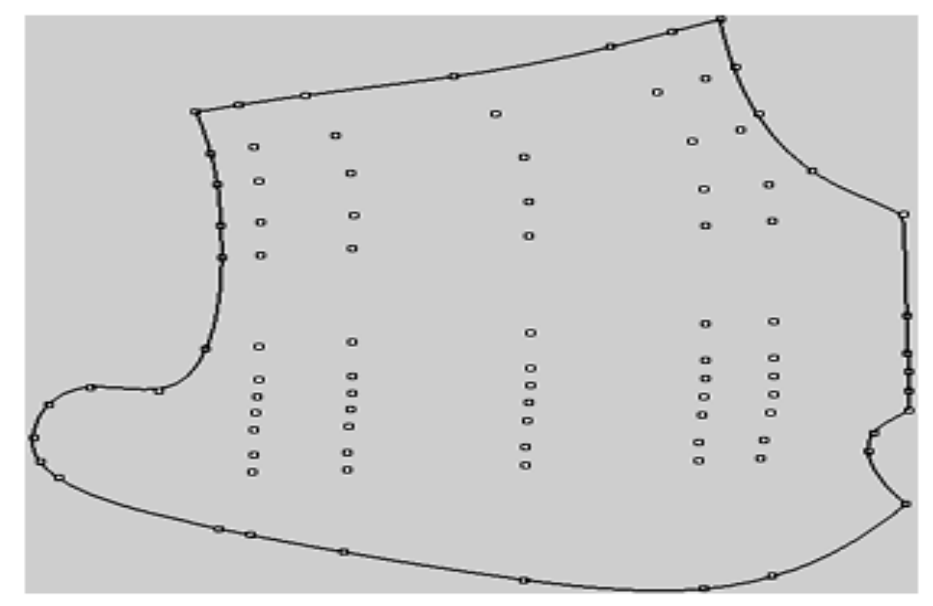

Fig 9. The given data points of complicated surface 


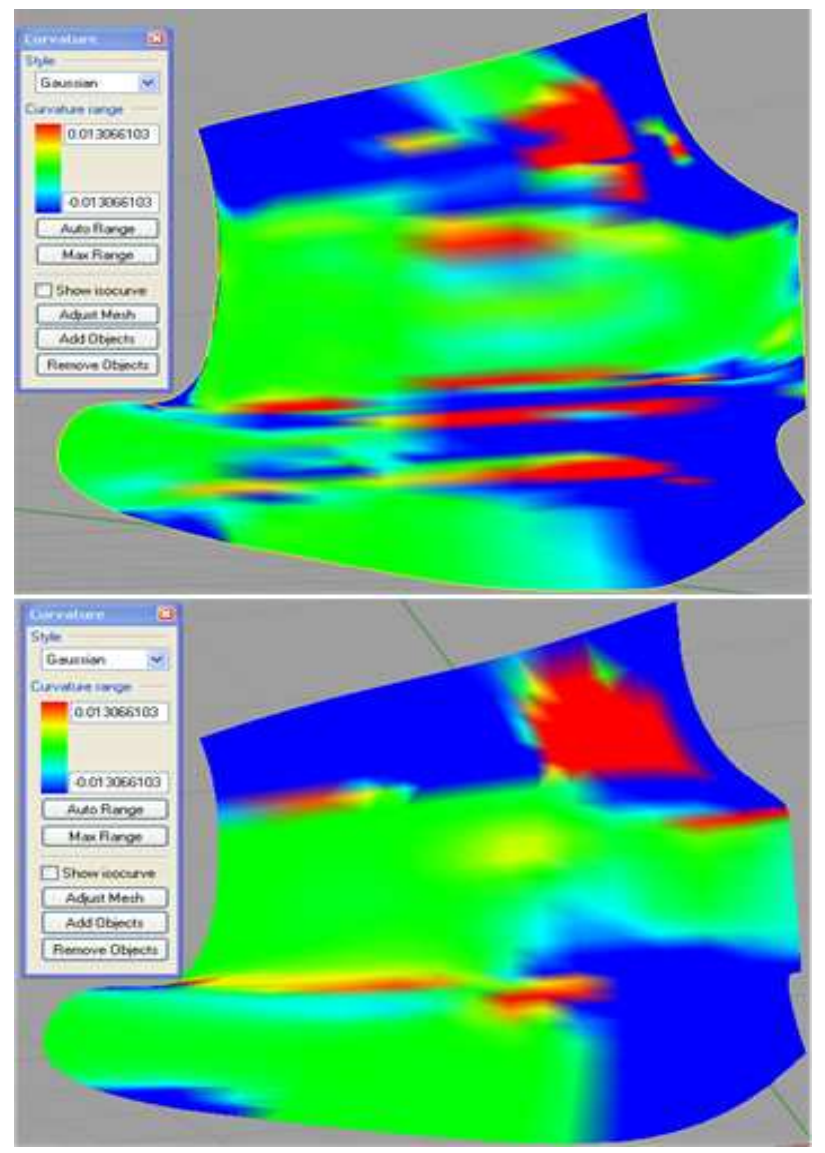

Fig 10. The Gaussian curvature of the complicated surface at 1 st generation and 20,000th generation

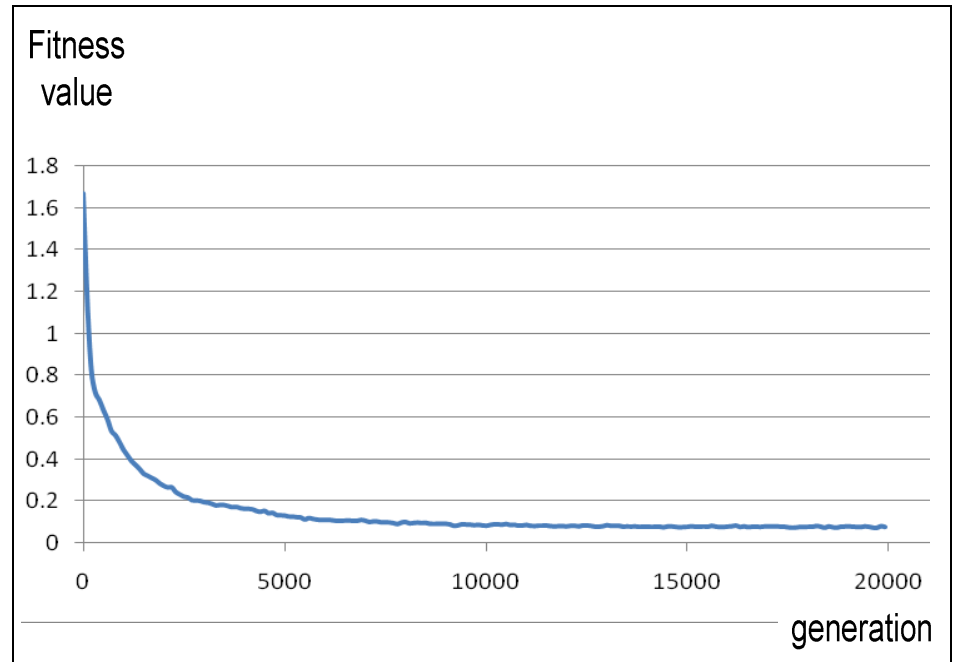

Fig 11. The fitness value during generations of complicated shape 
Table 2. Normalized error between the given data points and the complicated surface points

\section{CONCLUSIONS}

In this study, a NUB surface is generated in a fully automatic approach to the location of vertex points and knot value until satisfactory precision is reached. The main contribution of this research is to construct the NUB surface by using GA implementation for the optimization. All the above techniques have been implemented in a NUB surface generation effectively. As application examples, this technique represents the high visual quality in the case of a hull ship surface and complicated shape. The accuracy of each surface modeling is dependent on the generation time of the GA

\begin{tabular}{|c|c|}
\hline Computing time & Normalized error \\
\hline $30 \mathrm{~min}$ & 0.001461274 \\
\hline
\end{tabular}

process, while the convergent solution is guaranteed by the required precision.

The department of NAME of the HoChiMinh city University of Technology (HCMUT) since 2000 has studies and training courses in computer applications in ship hull design based on Maxsurf suite and other softwares [7]. The approach in this paper will be used as the extending for these courses. For future research in this study, emphasis should be on application of NURBS function in the finite element analysis and some steps for transferring of the geometry to the finite element mesh, thereby improvement the quality of the numerical models.

\title{
MÔ HÌNH HÓA BỀ MẶT TRONG CAD/CAM DỰA TRÊN THUẬT TOÁN NURBS
}

\author{
Lê Tất Hiển ${ }^{(1)}$, Nguyễn Xuân Hùng ${ }^{(2)}$, Võ Trọng Cang ${ }^{(1)}$ \\ (1) Trường Đại học Bách Khoa, ĐHQG-HCM \\ (2) Trường Đại học Khoa học Tự nhiên, ĐHQG-HCM
}

TÓM TẮT: Trong quá trình thiết kế số, mô hình hóa bề mặt yêu cầu độ chính xác cao nhằm hỗ trọ̣ hiệu quả cho các lĩnh vục sản xuất cũng nhu là công việc tích toán số. Bài báo trình bày nhũng kỹ thuật mô phỏng bề mặt dụa trên thuật toán NURBS (non-uniform rational B-spline). Các mặt NURBS có thể dễ dàng dịch sang nhiều phần mềm CAD/CAM, thuận lợi trong công việc mô phỏng và ưng dụng các phương pháp tính toán phần tử hưu hạn..

Tù khóa: Mô hình hóa bề mặt, NURBS, CAD/CAM, mô phỏng. 


\section{REFERENCES}

[1] B. K. Choi, Surface Modeling for CAD/CAM, Elsevier Amsterdam Oxford - New York - Tokyo Book (1991).

[2] D. E. Goldberg, Genetic algorithm in search, optimization, and machine learning, Addison-Wesley Book chapter (1989).

[3] D. F. Rogers, S. G. Satterfield, F. A. Rodriguez, Ship Hulls, B-spline Surfaces and CAD/CAM. IEEE, 02721716 (1983).

[4] F. Yoshimoto, T. Harada, M. Moriyama, Y. Yoshimoto, Data Fitting with a Spline using a Real Coded Genetic Algorithm, Comput Aided Design, Vol. 35, 751-760 (2003).
[5] R. W. Birmingham, T. A. G. Smith, Automatic Hull Form Generation: a practical tool for design and research, Proceedings of the Seventh International Symposium on Practical Design of Ships and Mobile Units, 281-287 (1988).

[6] T.H. Le, D. J. Kim, K. C. Min, S. W. Pyo, B-spline Surface Fitting using Genetic Algorithm, Journal of the Society of Naval Architectures of Korea, Vol. 46, 87-95 (2009).

[7] Vo Tr.Cang, Tran V.Tao, Geometric design of ships, Journal of Science \& Technology Development, Vol 4, No 5\&6, 13-19 (2001).

[8] W. Gordon, R. Riesenfeld, B-spline Curves and Surfaces, Comput Aided Geometric Des (Edited by Barnhill and Riesenfeld), Academic Press, 95126 (1974). 